\title{
CES
}

COOPERATIVISMO E ECONOMÍA SOCIAL

Núm. 41 (2018-2019), páxs. 307-322

ISSN: 1130-2682

\section{O FUNDO PARA A INOVAÇÃO SOCIAL E AS EMPRESAS SOCIAIS EM PORTUGAL}

\author{
THE SOCIAL INNOVATION FUND AND \\ SOCIAL ENTERPRISES IN PORTUGAL
}

\author{
MaÍra Fajardo Linhares Pereira*
}

\footnotetext{
* Doutoranda em Direito, Justiça e Cidadania no Século XXI na Universidade de Coimbra, Mestre em Direito Internacional e Integração Económica pela Universidade do Estado do Rio de Janeiro e advogada. Endereço de correio electrónico: mairafajardo@uol.com.br. Endereço postal: Faculdade de Economia da Universidade de Coimbra, Av. Dias da Silva, 165, 3004-512, Coimbra.
} 


\title{
RESUMO
}

O Decreto-Lei n. ${ }^{\circ}$ 28/2018 de 3 de maio criou o Fundo para a Inovação Social (FIS), quarto instrumento da Iniciativa Portugal Inovação Social. O FIS destaca-se dos demais instrumentos por ser o único a oferecer financiamentos reembolsáveis, prever retorno financeiro e incluir as sociedades sob a forma comercial que se qualifiquem como Pequenas e Médias Empresas como beneficiárias.

O objetivo desta crónica é fazer uma breve análise jurídica do Decreto-Lei n. ${ }^{\circ}$ 28/2018 no contexto do desenvolvimento do quadro legal português e do quadro legal europeu relativo às empresas sociais.

Palavras-Chave: Fundo para a Inovação Social; Portugal Inovação Social; investimento social; empresas sociais; sociedades comerciais.

\begin{abstract}
Decree-Law No. 28/2018 of May 3 created the Fund for Social Innovation (FIS), the fourth instrument of the Portugal Social Innovation Initiative. The FIS stands out from the other instruments because it is the only one to offer repayable financing, predict financial return and include limited liability companies and joint-stock companies qualify as Small and Medium Enterprises as beneficiaries.

The purpose of this article is to provide a brief legal analysis of Decree-Law No 28/2018 in the context of the development of the Portuguese legal framework and the European legal framework for social enterprises.

KeYwords: Fund for Social Innovation; Portugal Social Innovation Initiative; social investment; social enterprises; limited liability companies and joint-stock companies.
\end{abstract}


SUMÁRIO: 1. INTRODUÇÃO. 2. O FIS E A REGULAÇÃO DAS EMPRESAS SOCIAIS EM PORTUGAL. 2.1. Contextualização legal do Decreto-Lei n. ${ }^{\circ}$ 28/2018 no quadro legal português e no quadro legal europeu. 2.2. Conceituação e natureza do FIS. 2.3. Os beneficiários do FIS. 2.4. Sobre as condições de sustentabilidade financeira dos beneficiários do FIS. 2.5. O Decreto-Lei 28/2018 e o conceito normativo de empresa social. 3. CONSIDERAÇÕES FINAIS. 4. BIBLIOGRAFIA.

CONTENTS: 1. INTRODUCTION. 2. FIS AND THE REGULATION OF SOCIAL ENTERPRISES IN PORTUGAL. 2.1. Legal context of Decree-Law No 28/2018 in the Portuguese legal framework and in the European legal framework. 2.2. Concept and nature of FIS. 2.3. The beneficiaries of the FIS. 2.4. On the conditions of the financial sustainability of the beneficiaries of the FIS. 2.5. Decree-Law 28/2018 and the normative concept of social enterprise. 3. FINAL CONSIDERATIONS. 4. BIBLIOGRAPHY.

\section{INTRODUÇÃO}

$\mathrm{O}$ objetivo desta crónica é fazer uma breve análise jurídica do Decreto-Lei n. ${ }^{\circ}$ 28/2018 de 3 de maio que criou o Fundo para a Inovação Social (FIS) no contexto do desenvolvimento do quadro legal português e do quadro legal europeu relativo às empresas sociais ${ }^{2}$. Interessante observar desde já que, apesar de o FIS poder ser considerado pelas suas características um fundo de investimentos em empresas sociais, o Decreto-Lei não faz uso da expressão empresa social. Os possíveis motivos e implicações desta opção serão abordados ao longo da crónica.

O FIS é um dos quatro instrumentos de financiamento que compõem a Iniciativa Portugal Inovação Social e se destaca dos demais por ser o único que incluiu, até o momento, as sociedades sob a forma comercial que se qualifiquem como Pequenas e Médias Empresas como beneficiárias e cuja natureza dos financiamentos concedidos é reembolsável e prevê retorno financeiro.

\section{O Fis E A REgulaÇão DaS EMPRESAS SOCIAIS EM PORTUGaL}

\subsection{Contextualização legal do Decreto-Lei n. $^{\circ}$ 28/2018 no quadro legal português e no quadro legal europeu}

O FIS é um dos quatro instrumentos de financiamento que compõem a iniciativa pública Portugal Inovação Social, cuja execução é coordenada pela Estrutura

\footnotetext{
2 Uma análise do mesmo Decreto-Lei enquanto política pública foi feita em QUINTÃO, C./MARTINHO, A. L. «Crónicas da Iniciativa Portugal Inovação Social. Aprofundamento Crítico do Debate a Propósito do Fundo de Inovação Social», CES n. ${ }^{\circ}$ 40, (2017-2018), p. 411-423.
} 
de Missão Portugal Inovação Social (EMPIS) e que "visa promover a inovação social e dinamizar o mercado de investimento social em Portugal". ${ }^{3}$

A Portugal Inovação Social foi criada no âmbito do Acordo de Parceria entre Portugal e a Comissão Europeia designado Portugal 2020 e que regula a mobilização de Fundos Europeus Estruturais e de Investimento (FEEI), especificamente o Fundo Social Europeu (FSE), para Portugal no período 2014-2020 ${ }^{4}$. As disposições comuns dos FEEI foram estabelecidas no Regulamento (UE) n. ${ }^{\circ}$ 1303/2013, complementado pelo Regulamento Delegado (UE) n. ${ }^{\circ}$ 480/2014. Em Portugal, o Decreto-Lei n. ${ }^{\circ}$ 159/2014 de 27 de outubro estabeleceu as regras gerais de aplicação dos programas financiados pelos FEEI para o período de programação 20142020.

A Iniciativa Portugal Inovação Social e a EMPIS foram implementadas pela Resolução do Conselho de Ministros (RCM) n. ${ }^{\circ}$ 73-A/2014, alterada posteriormente pelas Resoluções do Conselho de Ministros n. ${ }^{\circ}$ 74/2016, n. ${ }^{\circ}$ 157/2017 e n. ${ }^{\circ} 177 / 2018$.

A Resolução 157/2017 alterou a redação das quatro alíneas do número 2 da Resolução 73-A/2014 que traz as definições dos quatro instrumentos de financiamento da Portugal Inovação Social. A Resolução 177/2018 alterou apenas as alíneas c) e d), referentes ao Programa de Parcerias para o Impacto (PPI) e ao Programa de Capacitação para o Investimento Social (PCIS) ${ }^{5}$.

\subsection{Conceituação e natureza do FIS}

Inicialmente, na Resolução 37-A/2014, o FIS é descrito como sendo "de natureza grossista com fundos participados, para apoio a iniciativas e investimentos

\footnotetext{
3 Ver Portugal Inovação Social - Sobre - O que fazemos, disponível em https://inovacaosocial. portugal2020.pt/sobre/portugal-inovacao-social/, consultado no dia 09 de julho de 2019.

4 ALMEIDA, F./SANTOS, F. «Portugal Inovação Social: na encruzilhada dos tempos», CES n. ${ }^{39}$, (2016-2017), p. 443-462.

5 A principal alteração na definição dos Títulos de Impacto Social foi terem passado de apoios reembolsáveis para apoios não reembolsáveis, outra alteração é referente ao objetivo do financiamento, antes financiar soluções inovadoras na prestação de serviços públicos e depois financiar projetos de inovação em áreas de prioridades de políticas públicas. A diferença da primeira versão da definição do Programa de Parcerias para o Impacto para a segunda versão é o destaque dado às fundações e misericórdias entre as entidades da economia social e a menção às fases das iniciativas de inovação e empreendedorismo a serem suportadas, embrionária ou exploratória, na primeira versão e a inclusão dos investidores sociais como cofinanciadores na segunda. Já a definição do Programa de Capacitação para o investimento foi alterada de vales de capacitação para apoios não reembolsáveis e os destinatários passaram a ser identificados como sendo as entidades da economia social. A Resolução 177/2018 trouxe a mesma alteração para o PPI e para o PCIS, ambos passaram a incluir entre seus beneficiários, entidades públicas e entidades privadas juntamente com as entidades da economia social. Esta alteração foi feita possivelmente para permitir a inclusão das sociedades sob forma comercial nas próximas candidaturas como está sendo feito no caso do FIS.
} 
em inovação e empreendedorismo social em fase de consolidação ou disseminação, através da concessão de empréstimos, bonificação de juros, prestação de garantias ou quase-capital”. Já na Resolução 157/2017, o FIS passa a ser descrito como "apoios para permitir acesso ao financiamento de projetos de inovação e empreendedorismo social, nomeadamente, através de instrumentos de dívida, incluindo mecanismos de cofinanciamento e de garantia, e de capital".

Como pode ser observado, o FIS teve não somente a sua natureza alterada, de fundo de fundos para fundo autónomo, mas também a natureza de seus instrumentos de financiamento, passando a incluir instrumentos de capital.

Inicialmente, o FIS foi pensado para ser um fundo grossista, sendo assim os beneficiários seriam os intermediários financeiros, ou seja, os gestores dos fundos retalhistas $^{6}$, e não as organizações implementadoras de Iniciativas de Inovação e Empreendedorismo Social (IIES) como previsto no Decreto-Lei 28/2018.

Possivelmente quando foi pensado como um fundo de fundos, levou-se em consideração os fundos de empreendedorismo social instituídos e regulados pelo Regime Jurídico do Capital de Risco, do Empreendedorismo Social e do Investimento Especializado (RJCRESIE) aprovado pela Lei n. ${ }^{\circ}$ 18/2015 de 04 de março e alterado pelo Decreto-Lei n. ${ }^{\circ} 56 / 2018$ de 9 de julho. A questão é que a instituição e regulação dos fundos não foi suficiente para o seu desenvolvimento em Portugal, em parte devido às incertezas em relação à própria definição de investimento em empreendedorismo social e, consequentemente, da identificação dos beneficiários destes fundos ${ }^{7}$.

$\mathrm{O}$ artigo $4^{\circ}$ do RJCRESIE definiu investimento em empreendedorismo social como sendo "a aquisição, por período de tempo limitado, de instrumentos de capital próprio e de instrumentos de capital alheio em sociedades que desenvolvem soluções adequadas para problemas sociais, com o objetivo de alcançar incidências sociais quantificáveis e positivas". Sendo assim, os beneficiários dos fundos

\footnotetext{
6 PROGRAMA OPERACIONAL INCLUSÃO SOCIAL E EMPREGO (PO ISE), ESTRUTURA MISSÃO PORTUGAL INOVAÇÃO SOCIAL (EMPIS), Fundo para a Inovação Social - Estratégia de Investimento - (versão em 12/11/2015 PO ISE / EMPIS), 2015.

7 A regulação dos fundos de empreendedorismo social e das sociedades de empreendedorismo social foi objeto de análise no artigo SOVERAL MARTINS, A. de. «Sociedades de Empreendedorismo Social e Fundos de Empreendedorismo Social: A Lei 18/2015, de 4 de março», CES, n. ${ }^{\circ} 38$, (2015-2016), p. 375-386. O artigo afirma que o regulamento gerou muitas dúvidas, o que dificulta o desenvolvimento deste tipo de investimento, porque para investir os investidores necessitam de certeza. $\mathrm{O}$ artigo aprofunda inclusive a análise sobre a natureza dos fundos de empreendedorismo social instituídos pela lei, se de fundo autónomo ou de organismo de investimento coletivo. Sobre os fundos de empreendedorismo social previstos no RJCRESIE ver também DIAS GONÇAVES, J. L. «As empresas sociais e o seu financiamento: as sociedades e os fundos de empreendedorismo social», Direito das Sociedades em Revista, ano 10, vol. 21, (2019), p. 197-218, para este autor os fundos de empreendedorismo social são organismos de investimento coletivo, assim como as sociedades de empreendedorismo social também o são.
} 
de empreendedorismo social seriam as sociedades que desenvolvem soluções adequadas para problemas sociais.

Esta definição do RJCRESIE gerou discussão por causa da palavra sociedades. Em Portugal, o empreendedorismo social é associado às organizações da economia social (OES), organizações estas previstas no artigo $4^{\circ}$ da lei de Bases da Economia Social - Lei n. ${ }^{\circ}$ 30/2013 de 8 de maio: cooperativas; associações mutualistas; misericórdias; fundações; instituições particulares de solidariedade social; associações com fins altruísticos que atuem no âmbito cultural, recreativo, do desporto e do desenvolvimento local; entidades abrangidas pelos subsectores comunitários e autogestionário, integrados nos termos da Constituição no sector cooperativo e social; outras entidades dotadas de personalidade jurídica, que respeitem os princípios orientadores da economia social previstos no artigo 5.o da Lei de Bases e constem da base de dados da economia social. A princípio, as sociedades não podem ser consideradas OES. O objeto da controvérsia não ficou restrito ao uso da palavra sociedades, mas também incluiu os instrumentos de investimento mencionados na definição, instrumentos de capital próprio e de capital alheio, instrumentos estes típicos do investimento em capital de risco em sociedades tradicionais, com objetivos lucrativos. Ou seja, mesmo que o RCRESIE tivesse usado outra expressão, como OES ao invés de sociedades, a controvérsia não seria muito menor, dado que a forma jurídica das OES não suporta investimentos em capital. A crítica à adequação da realização de investimento por meio dos instrumentos de capital relaciona-se também com o tipo de retorno oferecido ao investidor, associado a ganhos financeiros obtidos por meio da valorização das participações adquiridas ou por meio do recebimento de dividendos, o que no caso das OES também não é permitido por serem organizações sem fins lucrativos.

O formato inicial do FIS parece ser sido pensado exclusivamente para as OES e, provavelmente por isso, previu apenas o uso de instrumentos de quase-capital e não instrumentos de capital.

Os instrumentos de quase-capital pensados para o formato inicial do FIS foram os do tipo Revenue Participation Agreements (RPA) ou acordos de participação em receitas. Estes acordos "assumem a forma de contribuições financeiras não garantidas cujo reembolso está dependente do sucesso da IIES, recebendo o investidor uma percentagem das receitas geradas pelas iniciativas desenvolvidas com o apoio desse investimento". Este tipo de acordo talvez pudesse ser feito pelas OES por estarem associados à geração de receitas e não de lucros.

Em seu formato atual, o FIS é um fundo autónomo, isto é, constitui um patrimônio autónomo sem personalidade jurídica, mas com personalidade judiciária ${ }^{9}$,

8 PROGRAMA OPERACIONAL INCLUSÃO SOCIAL E EMPREGO (PO ISE), ESTRUTURA MISSÃO PORTUGAL INOVAÇÃO SOCIAL (EMPIS), 2015, p.1-17 (6).

9 Art. $15^{\circ}, 1$ da Lei n. ${ }^{\circ}$ 18/2015 de 04 de março. 
e tem por objeto a realização de dois tipos de operação: (i) operações de coinvestimento de capital e quase capital (FIS Capital) e (ii) operações de facilitação de acesso ao financiamento (FIS Crédito).

\subsection{Os beneficiários do FIS}

Os beneficiários deste instrumento de financiamento, ao contrário dos beneficiários dos outros instrumentos previstos na Portugal Inovação Social, devem apresentar condições de sustentabilidade financeira que permitam o posterior reembolso dos investimentos, já que a natureza dos financiamentos concedidos pelo FIS, além de ser reembolsável, prevê retorno financeiro. São beneficiários finais do FIS as sociedades sob forma comercial que se qualifiquem como PME e as OES, em ambos os casos, implementadoras de IIES.

As sociedades sob a forma comercial que se qualificam como PME são aquelas certificadas de acordo com o processo previsto no Decreto-Lei n. ${ }^{\circ}$ 372/2007 de 6 de novembro, alterado pelo Decreto-Lei n. ${ }^{\circ} 143 / 2009$ de 16 de junho e pelo Decreto-Lei n. ${ }^{\circ} 81 / 2017$ de 30 de junho. Interessante observar que o Decreto-Lei n. ${ }^{\circ}$ 372/2007 adota a definição de PME prevista na Recomendação n. ${ }^{\circ}$ 2003/361/ $\mathrm{CE}$, da Comissão Europeia, de 6 de maio, e considera empresa como sendo "qualquer entidade que, independentemente da sua forma jurídica, exerce uma atividade económica"10. Sendo assim, de acordo com o Decreto-Lei 372/2007, outras entidades também podem ser certificadas como PME, no entanto, somente podem ser beneficiárias do FIS as PME que sejam sociedades sob forma comercial ${ }^{11}$. Isto se justifica porque somente organizações no formato de sociedades comerciais estão aptas a se beneficiarem dos instrumentos previstos nas operações de coinvestimento de capital.

Já as OES são aquelas previstas na Lei de Bases. Todas elas podem ser beneficiárias dos instrumentos previstos para as operações de facilitação de acesso ao financiamento, sendo que as sociedades sob forma comercial também podem ser beneficiárias destes instrumentos.

\subsection{Sobre as condições de sustentabilidade financeira dos beneficiários do FIS}

Sobre as condições de sustentabilidade financeira, o Decreto-Lei não traz muita informação.

A responsabilidade pela averiguação da sustentabilidade financeira, cabe assim, a duas entidades diferentes, consoante o instrumento. No caso do FIS Capital,

${ }^{10}$ Art. $1^{\circ}$ do Anexo do Decreto-Lei 372/2007 de 6 de novembro.

${ }^{11}$ V. art. $1^{\circ}$, n. 4, do Código das Sociedades Comerciais. 
a responsabilidade é da PME Investimentos, entidade gestora do FIS e encarregue de todos os processos administrativos e operacionais, que avalia a capacidade de o negócio permitir o retorno do investimento ${ }^{12}$.

De acordo com a alínea f) do artigo $13^{\circ}$ do Decreto-Lei, a entidade gestora é quem tem competência para analisar e propor ao comitê de investimento os investimentos do FIS Capital, previstos no artigo $3^{\circ}$, que deverão, então, após a proposta da entidade gestora, ser aprovados pelo comitê de investimento de acordo com o número 1 do artigo $12^{\circ}$.

A PME Investimentos - Sociedade de Investimento, S. A., após convite feito pela Autoridade de Gestão do Programa Operacional Temático Competitividade e Internacionalização (COMPETE 2020), enviou proposta para a Ministra da Presidência e da Modernização Administrativa, para o ministro do Trabalho, Solidariedade e Segurança Social e para o Secretário de Estado do Desenvolvimento e Coesão que, conjuntamente, resolveram por designá-la, no Despacho n. ${ }^{\circ}$ 12106/2018, como entidade gestora do FIS, de acordo com o procedimento previsto no artigo $14^{\circ}$ do Decreto-Lei 28/2018.

Os critérios de admissão e seleção dos beneficiários finais do FIS Capital foram divulgados pela PME Investimentos. Entre estes critérios podem ser destacados três relacionados à apresentação de condições de sustentabilidade financeira: (i) A sociedade sob forma comercial candidata ao FIS Capital deve apresentar "uma situação económico-financeira equilibrada ou demonstrar capacidade de financiamento da operação"; (ii) o financiamento de risco a ser concedido deve basear-se em um "plano de atividades viável com informações pormenorizadas sobre o produto, as vendas e as perspetivas de rentabilidade, estabelecendo a viabilidade do investimento ex-ante"; (iii) o financiamento de risco deve ainda "ter subjacente uma estratégia de saída clara e realista"13.

No caso do FIS Crédito, a responsabilidade pela averiguação da sustentabilidade financeira é do departamento de risco do banco protocolado a quem o projeto recorreu. O banco avalia a capacidade do negócio de gerar receitas suficientes para pagar o empréstimo nos termos acordados ${ }^{14}$.

De acordo com a alínea g) do artigo $13^{\circ}$, a entidade gestora tem competência, não somente para analisar as operações a enquadrar no âmbito dos instrumentos do FIS Crédito, previstos no artigo $4^{\circ}$, mas também para aprová-las.

\footnotetext{
${ }^{12}$ Informações prestadas por e-mail recebido pela autora no dia 09 de julho de 2019 e enviado por João Machado, membro da Equipe Técnica de Financiamento do FIS.

${ }^{13}$ Fundo Inovação Social - Critérios de Admissão e Seleção, documento em formato pdf disponível em https://www.fis.gov.pt/wp-content/uploads/2019/04/Capital-Criterios-Selecao-e-Admissao-vf.pdf, baixado em 09 de julho de 2019.

${ }^{14}$ Informações prestadas por e-mail recebido pela autora no dia 09 de julho de 2019 e enviado por João Machado, membro da Equipe Técnica de Financiamento do FIS.
} 
Até o momento de elaboração desta crónica, o FIS Crédito ainda não estava com candidaturas abertas. $\mathrm{O}$ circuito de candidatura prevê a existência de bancos protocolados ${ }^{15}$ que farão a análise da operação de acordo com suas próprias políticas de risco. O banco poderá recusar a candidatura. No caso de aprovação, o banco enviará a proposta à sociedade de garantia mútua para obter uma garantia do valor de financiamento, que por sua vez, também de acordo com sua própria política de risco de crédito, decidirá sobre as condições de emissão da garantia. Em caso de aprovação pela sociedade de garantia mútua, o banco submeterá a candidatura à PME, entidade gestora, que deverá enquadrar e aprovar a proposta. Somente após a aprovação da PME, o banco e a sociedade de garantia mútua procederão à contratação do financiamento e da garantia ${ }^{16}$.

Apesar de a legislação não detalhar muito a questão da sustentabilidade financeira dos beneficiários, ela merece atenção.

Em geral, o conceito de sustentabilidade financeira não é abordado isoladamente, mas junto aos conceitos de sustentabilidade econômica, social e ecológica. Uma ideia comum presente nos diversos conceitos de sustentabilidade é a capacidade de um empreendimento de se manter para sempre, isto é, se manter mais ou menos constante ou estável, por um longo período, em termos institucionais, técnicos, políticos e financeiros. Desta forma, a sustentabilidade financeira pode ser entendida como a capacidade de uma entidade econômica auto prover recursos financeiros para manter sua exploração econômica, estando preparada inclusive para enfrentar os contratempos decorrentes ${ }^{17}$.

A sustentabilidade econômica tem sido uma das questões centrais nos debates, sejam sobre o empreendedorismo social, a economia social, as OES ou as empresas sociais. Discute-se como as organizações gerem seus recursos, quais métodos de gestão e processos de trabalho adotam. A questão atual parece ser a perceção da necessidade por parte das entidades com objetivos sociais da realização de algum tipo de atividade econômica orientada para o mercado que garanta excedentes suficientes para sua reprodução duradoura. Ao mesmo tempo que se discute como conciliar os objetivos econômicos com os objetivos sociais, discute-se ainda

${ }^{15} \mathrm{O}$ interesse das instituições bancárias portuguesas em participar do FIS Crédito ainda em sua primeira versão foi criticado, apontou-se questões referente a necessidade ou não da criação de uma nova área de negócio e os valores das taxas de retorno que se esperam mais baixas em relação aos produtos financeiros tradicionais. PARENTE, C./MARCOS, V./ QUINTÃO, C. «Portugal Inovação Social. Anotação à Resolução do Conselho de Ministros n. ${ }^{\circ}$ 73-A/2014, de 16 de dezembro de 2014», CES, n. ${ }^{\circ} 37,(2014-2015)$, p. 397-405 (401).

${ }^{16}$ Ver FIS Crédito - Circuito de Candidatura disponível em: https://www.fis.gov.pt/fis-credito-processo-de-candidatura/, consultado no dia 09 de julho de 2019.

${ }^{17}$ ALMEIDA FERNANDES, M. de/MEIRELES, M. «Justificativa e proposta de indicador de sustentabilidade financeira", Revista Contemporânea de Contabilidade», v. 10, n. 20 (mai./ago. 2013), p. 75-96 (77-78). 
se esta combinação é possível. A necessidade da geração de receitas próprias decorre da constatação da insuficiência de recursos, públicos ou privados, recebidos para manter o modelo de dependência financeira tradicionalmente associado às OES. Facto é que os recursos econômicos de uma organização que tem objetivos sociais costumam ser escassos ou tem tendência a escassez e parece ser consensual a busca pela geração de receitas próprias, seja por meio de um subproduto da atividade social, seja por um modelo de negócio lucrativo, para substituir ou, pelo menos diminuir o modelo de dependência ${ }^{18}$.

A questão prática do modelo de dependência ou de autossuficiência financeira das OES e das empresas sociais é indissociável do debate teórico ancorado em duas perspetivas, a estadunidense e a europeia, estando a questão da sustentabilidade mais relacionada à primeira. Uma das abordagens feitas pela perspetiva estadunidense é a da escola da gestão empresarial, responsável pelo desenvolvimento de uma análise "centrada nas preocupações de sustentabilidade econômica do setor não lucrativo baseadas numa forte orientação para o mercado e na eficácia dos métodos empresariais consideradas ferramentas para sobreviver e/ou prosperar". A entrada das organizações do setor não lucrativo na esfera comercial nos EUA ocorreu devido às razões de ordem estrutural em um contexto de retração econômica ${ }^{19}$.

A criação de instrumentos de financiamento mais adequados às necessidades específicas do setor da economia social juntamente com a melhora dos níveis de resposta das OES e com a contribuição para a sustentabilidade económica e financeira destas organizações estão entre os objetivos declarados, inclusive expressamente nos diversos documentos legais, relacionados à Portugal Inovação Social. A questão é saber se a oferta de financiamento por meio de instrumentos de capital é uma forma adequada para se atender estes objetivos.

Os instrumentos previstos no FIS são apontados como "mecanismos de financiamento complexos, organizados por lógicas, linguagens, metodologias e métricas próprias, bem como largamente ausentes da cultura e das práticas da maior parte das OES em Portugal"20. Esta observação vale tanto para o FIS Crédito quanto para o FIS Capital, no entanto no caso do FIS Capital não se trata apenas de instrumentos ausentes da cultura e da prática das OES, mas de instrumentos impossíveis de serem utilizados devido às formas jurídicas utilizadas por estas organizações. Uma questão é saber se, apesar de as sociedades sob a forma comercial não estarem previstas de forma expressa na Lei de Bases, existem atualmente em Portugal sociedades aptas a serem consideradas OES. Talvez existam e, neste

\footnotetext{
${ }^{18}$ PARENTE, C./QUINTÃO, C. «Capítulo 1 - Uma abordagem eclética ao empreendedorismo social», PARENTE, C., Empreendedorismo Social em Portugal, Universidade do Porto, 2014, p. 11-74 (40-47).

${ }^{19}$ PARENTE, C./QUINTÃO, C. p. 11-74 (26-29).

${ }^{20}$ QUINTÃO, C./ MARTINHO, A. L., p. 411-423 (420).
} 
caso, o FIS Capital vem atender uma necessidade específica do setor da economia social.

\subsection{O Decreto-Lei $28 / 2018$ e o conceito normativo de empresa social}

Neste ponto, entra a questão sobre a perceção do que sejam as empresas sociais em Portugal e de sua conceituação normativa. Em Portugal, não existe ainda um conceito normativo de empresa social, seja por meio da criação de um tipo legal ou de um status legal. O tipo legal prevê uma estrutura própria para o exercício da empresa social e o status legal oferece um reconhecimento a algumas entidades previstas em lei que atendem determinadas condições na sua prática econômica produtiva e que merecem, por isso, serem chamadas de empresas sociais.

No Relatório sobre Portugal no âmbito do estudo "A map of social enterprises and their eco-systems in Europe", realizado em 2014, concluiu-se que muitas das OES que operam sob diferentes formas legais poderiam se enquadrar no conceito de empresas sociais, especialmente aquelas com status de IPSS (Instituições Particulares de Solidariedade Social). O relatório menciona a possibilidade de empresas convencionais com missão social, isto é, sociedades sob a forma comercial com missão social, virem a serem consideradas empresas sociais, para isto deveriam ter um objetivo social claro e bem definido, assim como uma política de distribuição de lucros bem definida ${ }^{21}$.

Em 2019 foi feita uma atualização do relatório. O relatório de 2019 reafirma que não há nenhuma forma legal própria para as empresas sociais, mas que há algumas formas legais que que se alinham de perto à definição operacional das empresas sociais, seria o caso dos OES descritas na Lei de Bases da Economia Social, Instituições Privadas de Solidariedade Social e pessoas coletivas de utilidade pública. Como o anterior, destaca que nem todas as organizações mencionadas se enquadram como empresas sociais, que existe uma zona cinzenta, na qual inclui também a situação de algumas sociedades sob a forma comercial. Menciona que alguns estudos realizados em Portugal já identificaram sociedades sob a forma comercial como empresas sociais, mas destaca a importância do objeto social, do modelo de governança e da política de distribuição de dividendos para esta identificação ${ }^{22}$.

A doutrina também questiona o facto de sociedades poderem ser consideradas empresas sociais em Portugal, o facto de eventualmente uma sociedade ter por objeto atividades sociais ou ter objetivos de caráter social não é suficiente para

${ }^{21}$ EUROPEAN COMMISSION. A map of Social Enterprises and their ecosystems in Europe. Country Report for the Portugal. Authors: VAN DER VELDEN, M./ ALVAREZ, N./ SÁ, J. de/ MEIRA, D./ RAMOS, M. E. London, 2019.

${ }^{22}$ EUROPEAN COMMISSION. Social enterprises and their ecosystems in Europe. Updated country report: Portugal. Author: FERREIRA, S. Luxembourg: Publications, 2019. 
considerá-la uma empresa social. A sociedade não deixa, por isso, de estar integrada no setor privado, quer pelo escopo lucrativo, quer por apresentar gestão que não possa ser considerada democrática ${ }^{23}$. No entanto, há também quem ${ }^{24}$ defenda o contrário e argumente que o legislador pode vir a "criar um regime jurídico das empresas sociais que integre também pessoas coletivas que prossigam o lucro embora com limitação substancial na sua distribuição". ${ }^{25}$

Apesar de não usar a expressão empresa social, o Decreto-Lei 28/2018 trata-se sim de um documento legal relacionado às empresas sociais, isto porque a promoção da inovação e do empreendedorismo social e o desenvolvimento do mercado do investimento social, colocados ao mesmo tempo como objetivos e fundamentos da Portugal Inovação Social, estão diretamente relacionados com elas. A Portugal Inovação Social é um desdobramento, como visto do Portugal 2020, que por sua vez é um desdobramento do Europa 2020, instituído em 2010 e que resultou na produção de diversos documentos legais relacionadas às empresas sociais como a Iniciativa de Empreendedorismo Social de 2011 e o Regulamento (UE) n. ${ }^{\circ}$ 346/2013 do Parlamento Europeu e do Conselho de 17 de abril de 2013 relativo aos fundos europeus de empreendedorismo social (EUSEF), com uma conceção muito semelhante ao do FIS no que se refere a instrumentos de investimento e beneficiários e que tem por objetivo declarado no considerando 16, "apoiar o crescimento das empresas sociais na União". O documento sobre estratégia de investimento elaborado em conjunto pela PO ISE e pela EMPIS, afirma que o modelo proposto para o FIS "tem total enquadramento na regulamentação financeira nacional e comunitária aplicável", destacando o Regulamento dos EUSEF e o RJCRESIE ${ }^{26}$.

De certa forma, pode-se dizer então que o Decreto-Lei 28/2018 criou um conceito normativo implícito de empresa social por meio da criação de um status legal.

Como afirmado antes, o Decreto-Lei não faz uso da expressão empresa social, mas ao identificar os beneficiários do FIS como sendo as OES e as sociedades sob a forma comercial classificadas como PME, ambas implementadoras de IIES, destacou algumas entidades entre as OES e as sociedades sob a forma comercial, só faltou dizer que estas entidades destacadas são empresas sociais. Não dizer, foi

\footnotetext{
${ }^{23}$ COUTINHO DE ABREU, J. M. «Empresas Sociais (Nótulas de Identificação)». CES, n. ${ }^{\circ}$ 37, (2014-2015), p. 369-376 (375).

${ }^{24}$ SOARES FARINHO, D. «A sociedade comercial como empresa social - breve ensaio prospetivo a partir do direito positivo português». Revista do Direito das Sociedades, ano VII, (2015), 2, 247-270 (261).

${ }^{25}$ Sobre o tema ver também RAMOS, M. E. Direito Comercial e das Sociedades. Entre as empresas e o mercado. Coimbra: Almedina, 2018. p. 122-125.

${ }^{26}$ PROGRAMA OPERACIONAL INCLUSÃO SOCIAL E EMPREGO (PO ISE), ESTRUTURA MISSÃO PORTUGAL INOVAÇÃO SOCIAL (EMPIS), p.3.
} 
provavelmente uma escolha consciente, dado a polêmica existente em torno da regulação das empresas sociais em Portugal.

Interessante observar que a escolha pelo uso de outras expressões alusivas às empresas sociais no lugar da própria expressão aparece em documentos e artigos sobre o FIS. No documento sobre estratégia de investimento elaborado em parceria pelo PO ISE e pela EMPIS, usa-se startup sociais, ainda que inicialmente considere-se que elas devem assumir a forma jurídica das entidades da economia social. No entanto, a possibilidade de assumirem uma forma jurídica que permita constituir capital social também seja aventada no documento ${ }^{27}$. O atual e o ex-presidente da Portugal Inovação Social, coautores em um artigo sobre a iniciativa, também usam a expressão startup de missão social ao falar sobre o FIS, ainda em sua primeira definição ${ }^{28}$.

O facto é que apesar de não usar a expressão empresa social no Decreto-Lei isto não significa que o FIS não tenha sido criado para financiamento das empresas sociais em Portugal, até porque, como realidade prática, a existência das empresas sociais independe de conceituação legal. As empresas sociais não são criadas por lei, mas sim devem ser reguladas por ela.

O problema desta criação indireta de um status legal para as empresas sociais em Portugal por meio do Decreto-Lei que criou o FIS é que algumas questões relevantes no reconhecimento de uma prática econômica produtiva como prática de empresa social, como gestão e processo de decisão democráticos/participativos e, ainda mais fundamental, a política de distribuição de lucros, que a princípio deve ser restritiva devido a prevalência dos interesses sociais sobre os interesses lucrativos, não mereceram tratamento.

Para merecer o status implícito de empresa social e estar apto a participar do FIS, a entidade interessada, seja OES, seja sociedade sob a forma comercial, deve solicitar um parecer de avaliação à EMPIS sobre o projeto que pretende desenvolver. Se o projeto for qualificado como IIES pela EMPIS, será então analisado pela entidade gestora do FIS como previsto nas alíneas f) e g) do número 1 do artigo $14^{\circ}$.

Uma IIES “é um projeto que visa intervir, direta ou indiretamente, de forma inovadora e eficiente sobre um ou vários problemas sociais com o objetivo de gerar impacto social positivo". No questionário que deve ser respondido pelas entidades que querem ter um projeto reconhecido como IIES é solicitado, entre outros dados, a forma jurídica da organização; nome, descrição e localização de implementação do projeto; tipo de intervenção, se direta ou indireta; grupo alvo; problema social abordado; aspetos inovadores e diferenciadores de outras solu-

${ }^{27}$ PROGRAMA OPERACIONAL INCLUSÃO SOCIAL E EMPREGO (PO ISE), ESTRUTURA MISSÃO PORTUGAL INOVAÇÃO SOCIAL (EMPIS), p. 5-7.

${ }^{28}$ F. ALMEIDA, F. SANTOS, p. 459. 
ções; montante de investimento pretendido e estratégia para sua aplicação; identificação dos indicadores e metas utilizados para medir o sucesso de implementação do projeto ${ }^{29}$. Como se pode observar, o questionário avalia somente o projeto apresentado, apesar de ser a organização a beneficiária do FIS, ela não é avaliada. Desta forma, corre-se o risco de serem beneficiadas organizações, essencialmente sociedades sob a forma comercial, que possuem outros projetos além do projeto avaliado como IIES. Pergunta-se: será que organizações que possuem apenas um projeto classificado como IIES, podem ser consideradas como promotoras da inovação e do empreendedorismo social, enfim como empresas sociais, mesmo sem terem gestão participativa e, principalmente, não fazendo nenhuma alteração em relação à sua política de distribuição de lucros?

\section{CONSIDERAÇÕES FINAIS}

A promoção da inovação social e a dinamização do mercado de investimento social em Portugal por meio da criação de instrumentos de financiamento mais adequados às necessidades específicas do setor da economia social são objetivos legítimos e importantes. A questão, como visto, é saber se a oferta de financiamento por meio de instrumentos de capital é uma forma adequada para se atender estes objetivos.

Um dos pontos é o valor atribuído ao capital investido, que pode ser diferente no caso de uma empresa social sob o formato legal previsto para as OES ou sob o formato de sociedade comercial.

No caso das OES, o capital é um instrumento que as ajuda a serem socialmente úteis. Ao contrário do que ocorre nas empresas capitalistas, o capital não é o essencial para as OES, essencial é o que é produzido, o que é gerado pela atividade destas entidades ${ }^{30}$. Contudo, ainda que apenas um instrumento, uma maior oferta de capital para as entidades da economia social deve ser bem vista.

O FIS faz uma adaptação de instrumentos típicos do mercado capitalista para atendimento das necessidades da economia social. A fim de que este processo seja feito de forma a reforçar a economia social e não a subjugá-la, o direito deve realizar o seu papel, estipular as regras para o uso destes instrumentos, criando novas

\footnotetext{
${ }^{29}$ Ver FIS - Qualificação IIES - solicitar parecer, disponível em: https://www.fis.gov.pt/qualificacao-iies-parecer/, consultado no dia 09 de julho de 2019. O Regulamento Específico do Domínio da Inclusão Social e Emprego instituído na Portaria n. ${ }^{\circ}$ 97-A/2015 define, na alínea n) do artigo $2^{\circ}$, IIES como sendo "os projetos que preconizam respostas inovadoras que se distinguem das respostas tradicionais na resolução de problemas sociais pelo seu potencial de impacto e sustentabilidade". O Capítulo VII do Regulamento sobre Inovação Social aplica-se aos instrumentos de financiamento que compõem a Iniciativa Portugal Inovação Social, com exceção do FIS, de acordo com o artigo $223^{\circ}$.

${ }^{30}$ NAMORADO, R. O que é a economia social? - Economia Social em Textos. Número 1. Coimbra: CECES, 2017, p. 12.
} 
categorias e novas figuras jurídicas, se necessário, protagonizando o processo de imbricação crescente entre direito e sociedade de acordo com os princípios orientadores adotados por esta ${ }^{31}$.

Esta crónica termina deixando uma questão para reflexão. Uma leitura atenta do Decreto-Lei 28/2018 parece indicar que mais do que criar o FIS, o Decreto-Lei parece ter criado um conceito normativo implícito de empresa social por meio da criação de um status legal. Terá sido esta uma boa escolha no processo de construção do quadro regulador das empresas sociais em Portugal?

\section{BiBliografiA}

ALMEIDA, F./SANTOS, F. «Portugal Inovação Social: na encruzilhada dos tempos», CES n. ${ }^{\circ}$ 39, (2016-2017), p. 443-462.

ALMEIDA FERNANDES, M. de/MEIRELES, M. «Justificativa e proposta de indicador de sustentabilidade financeira", Revista Contemporânea de Contabilidade», v. 10, n. 20 (mai./ ago. 2013), p. 75-96.

COUTINHO DE ABREU, J. M. «Empresas Sociais (Nótulas de Identificação)». CES, n. ${ }^{\circ}$ 37, (2014-2015), p. 369-376.

DIAS GONÇAVES, J. L. «As empresas sociais e o seu financiamento: as sociedades e os fundos de empreendedorismo social», Direito das Sociedades em Revista, ano 10, vol. 21, (2019), p. 197-218.

EUROPEAN COMMISSION. A map of Social Enterprises and their ecosystems in Europe. Country Report for the Portugal. Authors: VAN DER VELDEN, M./ ALVAREZ, N./ SÁ, J. de/ MEIRA, D./ RAMOS, M. E. London, 2019.

EUROPEAN COMMISSION. Social enterprises and their ecosystems in Europe. Updated country report: Portugal. Author: FERREIRA, S. Luxembourg: Publications, 2019.

NAMORADO, R. O que é a economia social? - Economia Social em Textos. Número 1. Coimbra: CECES, 2017

PARENTE, C./MARCOS, V./ QUINTÃO, C. «Portugal Inovação Social. Anotação à Resolução do Conselho de Ministros n..$^{\circ}$ 73-A/2014, de 16 de dezembro de 2014», CES, n. ${ }^{\circ}$ 37, (20142015), p. 397-405.

PARENTE, C./QUINTÃO, C. «Capítulo 1 - Uma abordagem eclética ao empreendedorismo social», PARENTE, C., Empreendedorismo Social em Portugal, Universidade do Porto, 2014, p. 11-74.

PROGRAMA OPERACIONAL INCLUSÃO SOCIAL E EMPREGO (PO ISE), ESTRUTURA MISSÃO PORTUGAL INOVAÇÃO SOCIAL (EMPIS), Fundo para a Inovação Social Estratégia de Investimento - (versão em 12/11/2015 PO ISE / EMPIS), 2015.

QUINTÃO, C./MARTINHO, A. L. «Crónicas da Iniciativa Portugal Inovação Social. Aprofundamento Crítico do Debate a Propósito do Fundo de Inovação Social», CES n. ${ }^{\circ} 40$, (2017-2018), p. 411-423.

RAMOS, M. E. Direito Comercial e das Sociedades. Entre as empresas e o mercado. Coimbra: Almedina, 2018.

${ }^{31}$ R. NAMORADO, 2017, p. 20. 
SOARES FARINHO, D. «A sociedade comercial como empresa social - breve ensaio prospectivo a partir do direito positivo português». Revista do Direito das Sociedades, ano VII, (2015), 2, 247-270.

SOVERAL MARTINS, A. de. «Sociedades de Empreendedorismo Social e Fundos de Empreendedorismo Social: A Lei 18/2015, de 4 de março», CES, n. ${ }^{\circ} 38,(2015-2016), p$. 375-386. 